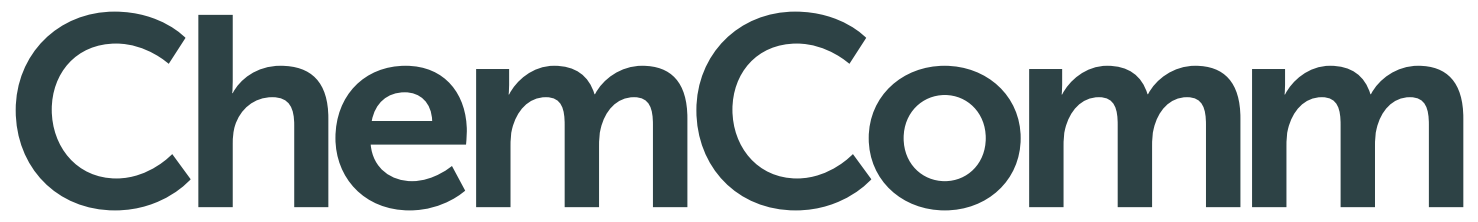

Chemical Communications

www.rsc.org/chemcomm
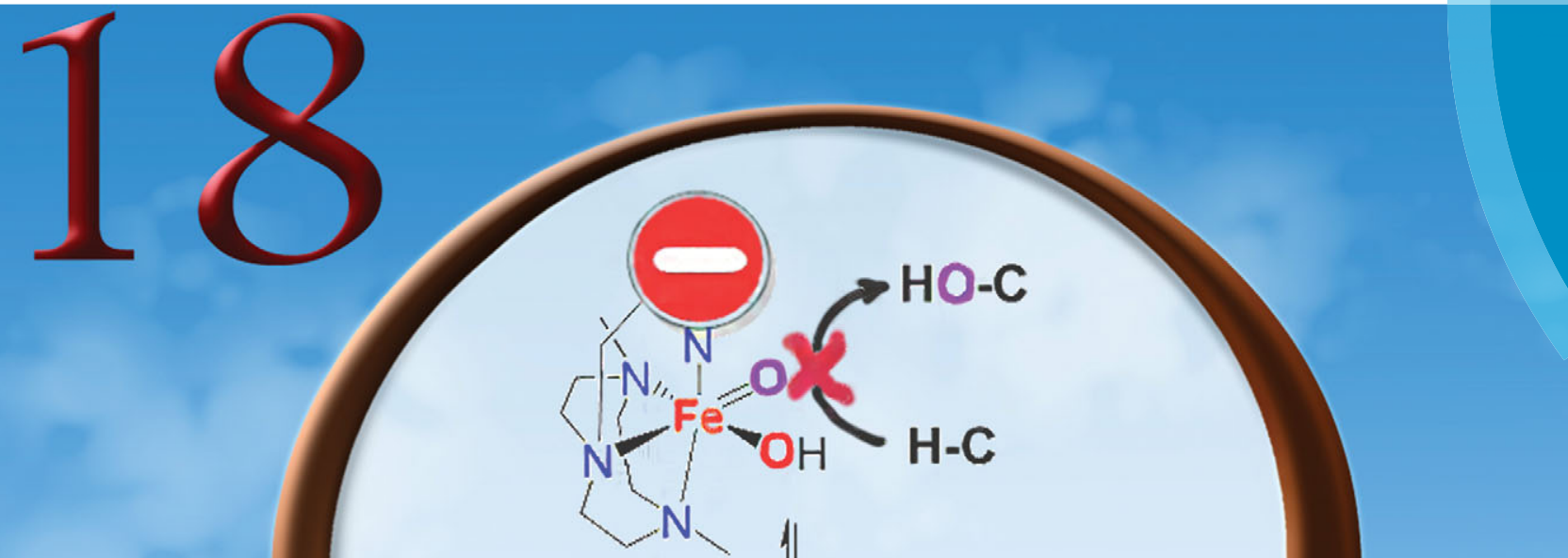

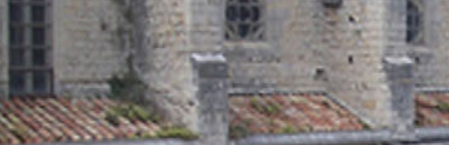
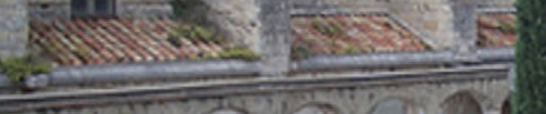

2.

(T) I

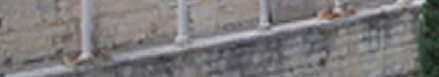

5. NAAAAA
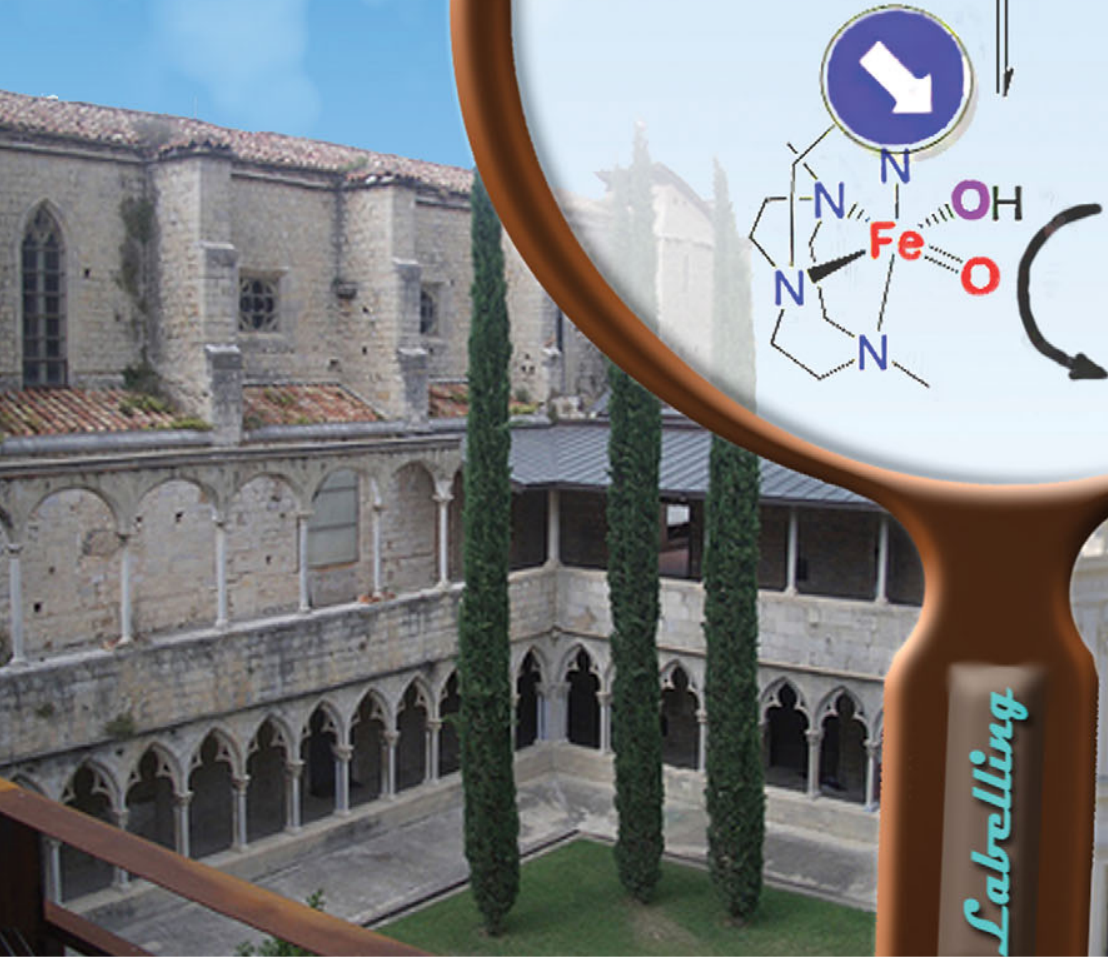

$\mathrm{H}-\mathrm{C}$
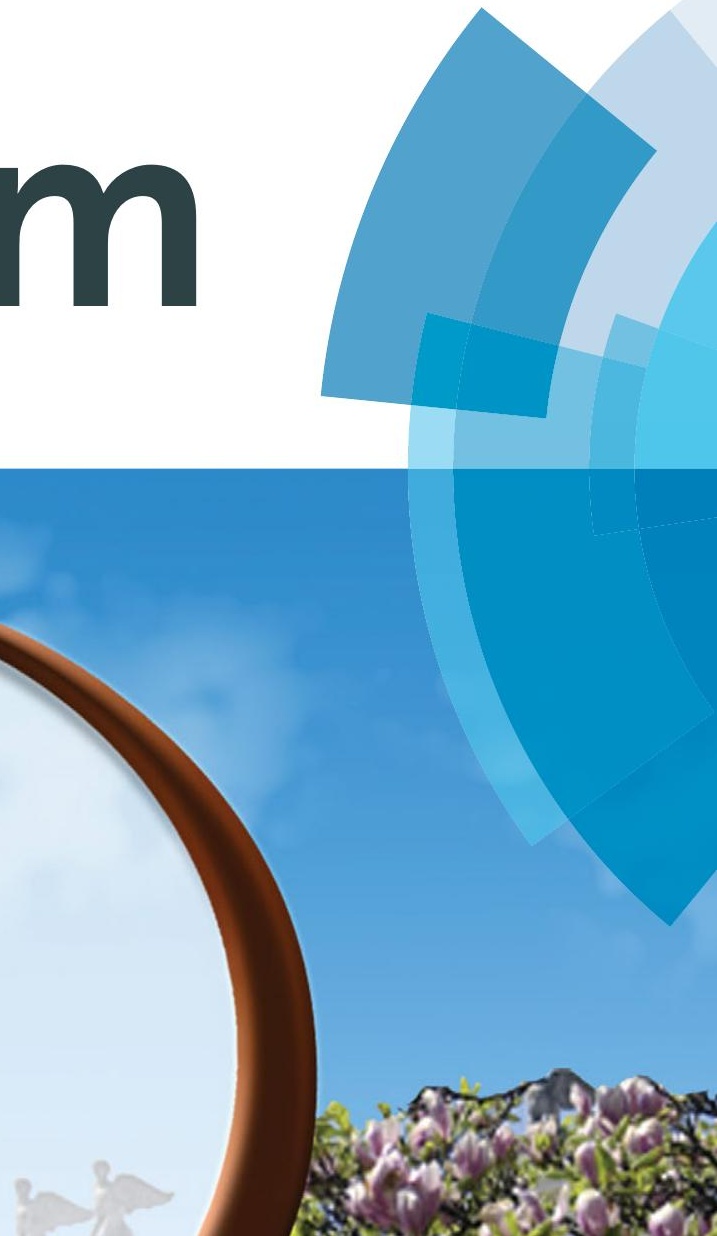

ISSN 1359-7345

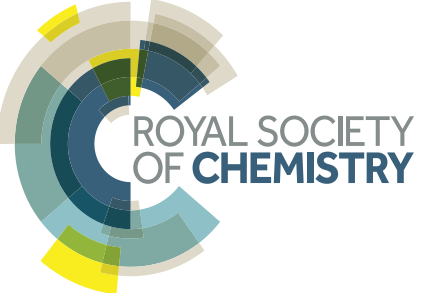




\section{Evidence that steric factors modulate reactivity of tautomeric iron-oxo species in stereospecific alkane $\mathrm{C}-\mathrm{H}$ hydroxylation $\dagger$}

50,1408

Received 11th October 2013,

Accepted 1st November 2013

DOI: $10.1039 / \mathrm{c3cc} 47830 \mathrm{k}$

www.rsc.org/chemcomm

\author{
Mainak Mitra, ${ }^{a}$ Julio Lloret-Fillol, ${ }^{\mathrm{b}}$ Matti Haukka, ${ }^{\mathrm{c}}$ Miquel Costas ${ }^{\star \mathrm{b}}$ and \\ Ebbe Nordlander ${ }^{\star a}$
}

\begin{abstract}
A new iron complex mediates stereospecific hydroxylation of alkyl $\mathrm{C}-\mathrm{H}$ bonds with hydrogen peroxide, exhibiting excellent efficiency. Isotope labelling studies provide evidence that the relative reactivity of tautomerically related oxo-iron species responsible for the $\mathrm{C}-\mathrm{H}$ hydroxylation reaction is dominated by steric factors.
\end{abstract}

While the selective functionalization of hydrocarbons remains a significant challenge for chemists, ${ }^{1}$ several iron-dependent oxygenases are able to mediate the hydroxylation of $\mathrm{C}-\mathrm{H}$ bonds under mild conditions, using dioxygen as the terminal oxidant. ${ }^{2}$ Examples include the cytochrome P450 enzymes, ${ }^{3}$ and the family of non-heme iron-dependent Rieske oxygenases. ${ }^{4}$ In both cases, $\mathrm{C}-\mathrm{H}$ hydroxylation occurs with almost complete stereoretention, and is accomplished via the intermediacy of an electrophilic high valent iron-oxo species that attacks the $\mathrm{C}-\mathrm{H}$ bond via the so-called oxygen-rebound mechanism (Scheme 1). ${ }^{5}$

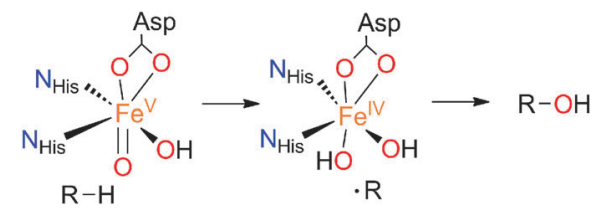

Scheme 1 Schematic mechanism for $\mathrm{C}-\mathrm{H}$ hydroxylation by a Rieske oxygenase enzyme.

\footnotetext{
${ }^{a}$ Chemical Physics, Department of Chemistry, Lund University, P.O. Box 124, Lund, SE-221 00, Sweden. E-mail: Ebbe.Nordlander@chemphys.lu.se; Fax: +46-46-22-24119; Tel: +46-46-22-28118

${ }^{b}$ QBIS Group, Department of Chemistry and Institut de Quimica Computacional $i$ Catalisi (IQCC), Universitat de Girona, Campus Montilivi, 17071 Girona,

Catalonia, Spain. E-mail: miquel.costas@udg.edu; Fax: +34-972-41-81-50; Tel: +34-972-41-98-42

${ }^{c}$ University of Jyväskylä, Department of Chemistry, P.O. Box 35, FI-40014 University of Jyväskylä, Finland

$\dagger$ Electronic supplementary information (ESI) available: Ligand synthesis, complex synthesis, proton NMR spectra, ESI-MS and IR spectra of the complex, crystallographic data for complexes $\mathbf{1}^{\text {OTf }}$ and $\mathbf{1}^{\mathbf{H}_{2} \mathbf{O}}$, catalysis experiments and results and details of isotope labelling experiments. CCDC 960138 and 960139. For ESI and crystallographic data in CIF or other electronic format see DOI: $10.1039 / \mathrm{c} 3 \mathrm{cc} 47830 \mathrm{k}$
}

A fundamental difference between heme and non-heme sites is that active sites in the latter contain lower coordination numbers, and a number of them form reactive intermediates containing a cis$\mathrm{Fe}(\mathrm{O})(\mathrm{X})$ unit $(\mathrm{X}=\mathrm{HO}(\mathrm{H}), \mathrm{Cl}, \mathrm{Br})$. This leads to a versatile reactivity that opens new mechanistic scenarios. Arene cis-dihydroxylation and aliphatic chlorination constitute unique examples of the reactivity exhibited by cis- $\mathrm{Fe}(\mathrm{O})(\mathrm{X})$ units $(\mathrm{X}=\mathrm{OH}, \mathrm{Cl}$ and $\mathrm{Br}) .{ }^{4,5 b, 6}$

The reactivity of non-heme oxygenases has inspired the design of synthetic model complexes as selective $\mathrm{C}-\mathrm{H}$ oxidation catalysts. ${ }^{7}$ Mechanistic studies have shown that in selected cases reactions are metal based, involving high-valent oxo-iron species, and are fundamentally distinct from radical pathway Fenton processes. ${ }^{8}$ The Fe(PyTACN) family of complexes (Scheme 2) belongs to the group of catalysts that mediate $\mathrm{C}-\mathrm{H}$ hydroxylation with retention of configuration. ${ }^{8 d}$ We and others have proposed a mechanistic scenario resembling the "peroxide shunt"3 of cytochrome P450 and model systems. A highly electrophilic $\left[\mathrm{Fe}^{\mathrm{V}}(\mathrm{O})(\mathrm{OH})\left(\mathrm{L}^{\mathrm{N} 4}\right)\right]^{2+}$ oxidant $(\mathbf{O})$, formed via water-assisted cleavage of a hydroperoxide $\left[\mathrm{Fe}^{\mathrm{III}}(\mathrm{OOH})\right.$ $\left.\left(\mathrm{OH}_{2}\right)\left(\mathrm{L}^{\mathrm{N} 4}\right)\right]^{2+}\left(\mathbf{P}_{\mathbf{B}}\right)$ (Scheme 2), is ultimately responsible for $\mathrm{C}-\mathrm{H}$ oxidation reactions. ${ }^{8 a, d, 9-11}$ Intermediate $\mathbf{O}$ can exist as two tautomerically related species, $\mathbf{O}_{\mathbf{A}}$ and $\mathbf{O}_{\mathbf{B}}$, that differ in the relative positions of the oxo and hydroxide ligands, and are connected through prototopic oxo-hydroxo tautomerism. We have also previously studied $\mathrm{C}-\mathrm{H}$ oxidation reactions using a set of catalysts where electronic properties of the PyTACN ligand were systematically tuned, and found that the relative reactivity of $\mathbf{O}_{\mathbf{A}}$ and $\mathbf{O}_{\mathbf{B}}$ in $\mathrm{C}-\mathrm{H}$ oxidations remains basically the same, irrespective of the catalyst. ${ }^{8 d}$

In this work we turn our attention towards investigation of steric effects. Towards this end, $\mathrm{C}-\mathrm{H}$ oxidation reactions catalyzed

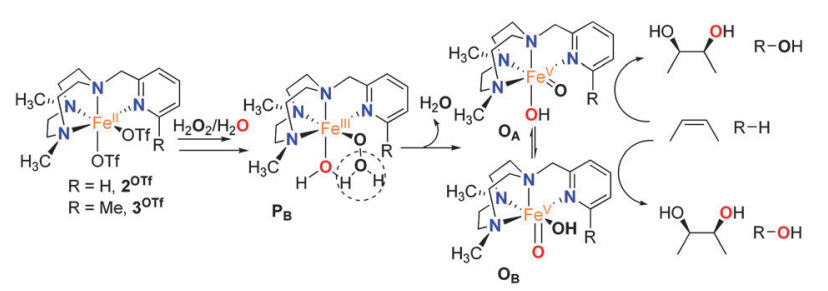

Scheme 2 Mechanism for substrate oxidation by Fe(PyTACN) complexes. 


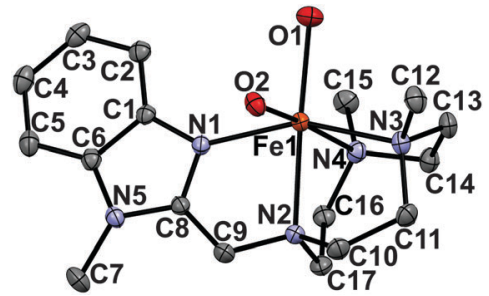

Fig. 1 Molecular structure of $\left[\mathrm{Fe}^{\prime \prime}\left(\mathrm{H}_{2} \mathrm{O}\right)_{2}\left(\mathrm{Me}_{2}, \mathrm{Bz} / \mathrm{m} T A C N\right)\right]^{2+}\left(1^{\mathrm{H}_{2} \mathrm{O}}\right)$ with $30 \%$ probability ellipsoids; $\mathrm{H}$-atoms have been omitted for clarity.

using the new iron complex $\left[\mathrm{Fe}^{\mathrm{II}}\left(\mathrm{CF}_{3} \mathrm{SO}_{3}\right)_{2}\left(\mathrm{Me}_{2}, \mathrm{BzIm}_{\mathrm{TACN}}\right)\right]$ (Fig. 1), $1^{\text {OTf }}$, were studied. The new tetradentate ligand ${ }^{\mathrm{Me}_{2}, \mathrm{BzIm}_{\mathrm{TACN}} \text { has }}$ been developed by replacing the pyridyl arm of the PyTACN scaffold by an $N$-methyl benzimidazolyl substituent. The $\mathrm{sp}^{2}$ character and the rigidity of the latter substituent should provide a well-defined steric demand, intermediate between the $\alpha-\mathrm{H}$ and the $\alpha$-Me groups of a pyridine (Scheme 2, catalysts $2^{\text {OTf }}$ and $3^{\text {OTf }}$ ). On the other hand, the relative donor capacities of pyridine and benzimidazole can be estimated to be very similar by comparing the $\mathrm{p} K_{\mathrm{a}}$ values of their conjugate acids (5.22 for pyridine, 5.41 for benzimidazole and 5.57 for $\alpha$-Me pyridine), and therefore differences in reactivity among this set of complexes can be traced to steric factors.

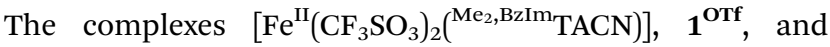
$\left[\mathrm{Fe}^{\mathrm{II}}\left(\mathrm{H}_{2} \mathrm{O}\right)_{2}\left({ }^{\mathrm{Me}_{2}, \mathrm{BzIm}} \mathrm{TACN}\right)\right]\left(\mathrm{CF}_{3} \mathrm{SO}_{3}\right)_{2}, \mathbf{1}^{\mathbf{H}_{2} \mathbf{O}}$, were prepared and characterized following standard procedures (see $\mathrm{ESI} \dagger$ for details). The X-ray structures of $\mathbf{1}^{\text {OTf }}$ and $\mathbf{1}^{\mathbf{H}_{2} \mathbf{O}}$ are very similar to those of $2^{\text {OTf }}$ and $3^{\text {OTf }}$ and have an iron center in a distorted octahedral environment surrounded by the four $\mathrm{N}$ atoms of the ligand, with the TACN ring capping one face of the octahedron, and two oxygen atoms of triflate anions $\left(\mathbf{1}^{\text {OTf }}\right)$ or water molecules $\left(\mathbf{1}^{\mathbf{H}_{2} \mathbf{O}}\right)$ cis to each other ( $c f$. Fig. 1 and ESI $\left.\dagger\right) .{ }^{8 d}$ Average Fe- $\mathrm{N}_{\mathrm{TACN}}$ and $\mathrm{Fe}-\mathrm{O}_{\mathbf{H}_{2} \mathbf{O}}$ distances are $2.23 \AA$ and $2.13 \AA$ respectively, characteristic of a high spin ferrous center. ${ }^{12}$

Complex $1^{\text {OTf }}$ was found to be an outstanding catalyst in C-H oxidation reactions with $\mathrm{H}_{2} \mathrm{O}_{2}$. Catalytic oxidation of cyclohexane was chosen for appropriate comparison with literature precedents. $^{8,13}$ Syringe pump addition of 10 equivalents (w.r.t. the complex) of $\mathrm{H}_{2} \mathrm{O}_{2}$ together with 1000 equivalents of $\mathrm{H}_{2} \mathrm{O} \neq$ to a $\mathrm{CH}_{3} \mathrm{CN}$ solution containing 1 and a substrate (1000 equivalents) over $30 \mathrm{~min}$ in air at room temperature resulted in the formation of cyclohexanol (A) with a turnover number (TON) of 8.5 and a small amount of cyclohexanone (K) with a TON of 0.8 , giving an alcohol/ketone $(\mathrm{A} / \mathrm{K})$ ratio of 10.6. The efficiency w.r.t. consumption of the oxidant was around $99-100 \%$, and remains unusually high (54\%) when 100 equiv. of $\mathrm{H}_{2} \mathrm{O}_{2}$ are employed. Interestingly, when followed over time, the $\mathrm{A} / \mathrm{K}$ product ratio in oxidation of cyclohexane showed that the initial value of $\mathrm{A} / \mathrm{K}$ was around 35, which gradually decreased to 10.6 ( $c f$. Fig. S5, ESI $\dagger$ ). This provides strong evidence that cyclohexanol is the almost exclusive primary product of the alkane oxidation reaction, and cyclohexanone is a result of further oxidation of the alcohol, thereby eliminating the significant implication of a Russelltype termination mechanism initiated by hydroxyl radicals and producing equal amounts of alcohol and ketone.
Several mechanistic probes further substantiate that the reactions are metal-based. The intermolecular kinetic isotope effect was determined for the formation of cyclohexanol from a mixture $(1: 3)$ of cyclohexane and its deuterated isotopomer cyclohexane- $\mathrm{d}_{12}$, and was found to be 5 . Also, complex $1^{\text {OTf }}$ oxidizes adamantane with a large $\mathrm{C} 3 / \mathrm{C} 2$ normalized selectivity (14) towards the tertiary $\mathrm{C}-\mathrm{H}$ bond. The oxidation of cis-1,2dimethylcyclohexane (DMCH) leads to the corresponding tertiary alcohol product with $97 \%$ retention of configuration. These data are consistent with the implication of selective oxidants whose relative reactivities against $\mathrm{C}-\mathrm{H}$ bonds are modulated by their bond strengths and steric properties. ${ }^{7 a}$ The reactivity of $\mathbf{1}^{\text {OTf }}$ against these mechanistic probes is thus in good accordance with that described for iron catalysts that mediate stereospecific C-H hydroxylation, including those of the [Fe(PyTACN)] family. ${ }^{8 d}$ Since these catalysts operate via a $\left[\mathrm{Fe}^{\mathrm{V}}(\mathrm{O})(\mathrm{OH})\left(\mathrm{L}^{\mathrm{N} 4}\right)\right]^{2+}(\mathbf{O})$ oxidant, ${ }^{8 a, d, 10,11}$ the same was tentatively inferred for $\mathbf{1}^{\text {oTf }}$. Strong experimental evidence in favor of this scenario arises from olefin cis-dihydroxylation reactions. The water assisted cleavage of the $\mathrm{O}-\mathrm{O}$ bond (Scheme 2) determines the oxygen atom inventory in the $\mathrm{HO}-\mathrm{Fe}^{\mathrm{V}}=\mathrm{O}$ oxidant $(\mathbf{O})$. One of the oxygen atoms originates from the water molecule, while the second oxygen atom is derived from the peroxide. cis-Dihydroxylation reactions incorporate both oxygen atoms of $\mathbf{O}$ into the product and consequently syn-diols must contain one oxygen atom that originates from water and one oxygen from the peroxide. ${ }^{11}$ Indeed, $1^{\text {OTf }}$ catalyzes the oxidation of cyclooctene $\left(1^{\text {OTf }}: \mathrm{H}_{2} \mathrm{O}_{2}: \mathrm{H}_{2}{ }^{18} \mathrm{O}\right.$ : cyclooctene, $1: 10: 1000: 1000)$ affording cis-cyclooctene epoxide (TON =2) and syn-cyclooctane-1,2-diol ( $\mathrm{TON}=7$ ). The syn-diol is $98 \%{ }^{16} \mathrm{O}^{18} \mathrm{O}$ labeled, providing strong support in favor of $\mathbf{O}$ as the oxidant.

Having obtained positive evidence that $1^{\text {OTf }}$ operates through the same mechanism as that of $2^{\text {OTf }}$ and $3^{\text {OTf }}$, we proceeded to investigate the relative reactivity of the $\mathbf{O}_{\mathbf{A}} / \mathbf{O}_{\mathbf{B}}$ tautomers in $\mathrm{C}-\mathrm{H}$ hydroxylation reactions. Since the origin of the oxygen atoms is determined in the peroxide precursor $\left(\mathbf{P}_{\mathbf{B}}\right)$, the relative reactivity of $\mathbf{O}_{\mathbf{A}}$ and $\mathbf{O}_{\mathbf{B}}$ in $\mathrm{C}-\mathrm{H}$ hydroxylation can be probed using isotopically labeled water and hydrogen peroxide (Scheme 2). The oxidation of cyclohexane by $\mathbf{1}^{\text {oTf }}$ in the presence of 10 equivalents of $\mathrm{H}_{2}{ }^{18} \mathrm{O}_{2}$ and 1000 equivalents of $\mathrm{H}_{2} \mathrm{O}$ afforded $45 \%{ }^{18} \mathrm{O}$-labeled cyclohexanol. Complementary experiments with 10 equivalents of $\mathrm{H}_{2} \mathrm{O}_{2}$ and 1000 equivalents of $\mathrm{H}_{2}{ }^{18} \mathrm{O}$ afforded $48 \%{ }^{18}$ O-labeled cyclohexanol (Table 1 ).

Similar levels of ${ }^{18} \mathrm{O}$-label incorporation from $\mathrm{H}_{2}{ }^{18} \mathrm{O}$ were observed in the case of cyclooctane $(41 \%)$ and cyclohexane- $\mathrm{d}_{12}$ $(48 \%)$. These levels of water incorporation are unusually high, only bypassed in the literature by $2^{\text {OTf }}, 8 d$ and constitute strong evidence that $\mathbf{O}_{\mathbf{A}}$ and $\mathbf{O}_{\mathbf{B}}$ are roughly equally reactive against secondary $\mathrm{C}-\mathrm{H}$ bonds. Most interestingly, when the substrates contain tertiary $\mathrm{C}-\mathrm{H}$ bonds (e.g. $\mathrm{DMCH}$ and adamantane), the percentages of ${ }^{18} \mathrm{O}$ incorporation from $\mathrm{H}_{2}{ }^{18} \mathrm{O}$ were found to be in the range $25-29 \%$, indicating a preferential oxidation via $\mathbf{O}_{\mathbf{A}}$.

Interpretation of these values can be done by considering those obtained using $2^{\text {OTf }}$ and $3^{\text {OTf }}$ in analogous reactions. Table 1 shows that hydroxylation of tertiary $\mathrm{C}-\mathrm{H}$ bonds mediated by $2^{\text {OTf }}$ is predominantly performed by $\mathbf{O}_{\mathbf{B}}$ as shown by the large extent of oxygen atoms originating from water in the alcohol 
Table 1 Comparison of percentage of ${ }^{18} \mathrm{O}$ incorporation into alcohol products by different $\mathrm{Fe}$-catalysts using 1000 equivalents of $\mathrm{H}_{2}{ }^{18} \mathrm{O}$

\begin{tabular}{|c|c|c|c|c|}
\hline$\overbrace{}^{H}$ & $\begin{array}{c}\text { Cat (1 equiv.) } \\
\mathrm{H}_{2}{ }^{16} \mathrm{O}_{2}(10 \text { equiv.) } \\
\mathrm{H}_{2}{ }^{18} \mathrm{O}(1000 \text { equiv. }) \\
\underset{\mathrm{CH}_{3} \mathrm{CN}, \mathrm{RT}}{\longrightarrow}\end{array}$ & & & \\
\hline Substrate & $1^{\text {OTf }}$ & $2^{\text {OTf }}$ & $3^{\text {OTf }}$ & $\mathrm{Fe}(\mathrm{TPA})^{b}$ \\
\hline Cyclohexane & 48 & 45 & 11 & 29 \\
\hline Cyclohexane- $\mathrm{d}_{12}$ & 48 & 40 & - & 35 \\
\hline Cyclooctane & 41 & 44 & - & 23 \\
\hline cis-DMCH & 26 & 79 & 2 & 6 \\
\hline Adamantane & 28 & 74 & 3 & 6 \\
\hline$c i s$-Cyclooctene epoxide ${ }^{a}$ & 24 & 77 & 5 & 9 \\
\hline syn-Cyclooctane-1,2-diol ${ }^{a}$ & 98 & 97 & 78 & 86 \\
\hline
\end{tabular}

${ }^{a}$ Cyclooctene was employed as a substrate. ${ }^{b}\left[\mathrm{Fe}(\mathrm{TPA})\left(\mathrm{CH}_{3} \mathrm{CN}\right)_{2}\right]^{2+}$, Ref. $8 \mathrm{a}$.

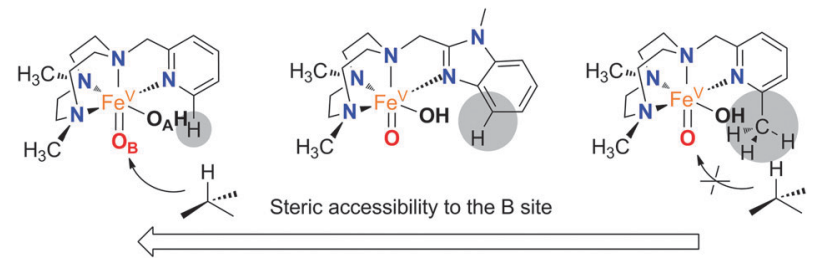

Fig. 2 Comparative analysis of the steric bulk in proximity to site B.

product (up to $79 \%, c f$. Table 1). Instead, hydroxylation of secondary $\mathrm{C}-\mathrm{H}$ bonds occurs with incorporation of $\sim 40 \%$ of oxygen atoms from water, suggesting comparable reactivity of both tautomers. In sharp contrast, hydroxylation catalyzed by $3^{\text {OTf }}$ exhibits a relatively small extent $(\sim 10 \%)$ of water incorporation in hydroxylation of secondary $\mathrm{C}-\mathrm{H}$ bonds, and negligible $(<3 \%)$ incorporation in the hydroxylation of tertiary $\mathrm{C}-\mathrm{H}$ sites, indicating that hydroxylation is almost exclusively performed by $\mathbf{O}_{\mathbf{A}}$.

Therefore, the relative reactivity of the two tautomeric forms of the $\left[\mathrm{Fe}^{\mathrm{V}}(\mathrm{O})(\mathrm{OH})\left(\mathrm{L}^{\mathrm{N} 4}\right)\right]^{2+}(\mathbf{O})$ intermediate is finely tuned among the series of catalysts $\left(\mathbf{1}^{\text {OTf }}-3^{\text {OTf }}\right)$, a fact that contrasts with the small effects exerted when the electronic properties of the pyridine in a series of catalysts is altered. ${ }^{8 d}$ Trends observed for $\mathbf{1}^{\text {OTf }}-3^{\text {OTf }}$ may thus be rationalized on the basis of steric effects. The benzylimidazole ring introduces steric bulk in the proximity of position $\mathrm{B}$ at the iron center that is intermediate between that set by pyridine and 6-Me-pyridine arms (Fig. 2). Accordingly, when secondary $\mathrm{C}-\mathrm{H}$ bonds are hydroxylated, $\mathbf{1}^{\text {OTf }}$ behaves as $2^{\text {OTf }}$, i.e. tautomers $\mathbf{O}_{\mathbf{A}}$ and $\mathbf{O}_{\mathbf{B}}$ are equally implicated in the $\mathrm{C}-\mathrm{H}$ oxidation reaction. On the other hand, oxidation of sterically more demanding tertiary $\mathrm{C}-\mathrm{H}$ bonds yields levels of water incorporation that suggest predominant participation of $\mathbf{O}_{\mathbf{A}}$ as in the case of $3^{\text {OTf }}$, although unlike in the latter case, implication of $\mathbf{O}_{\mathbf{B}}$ remains significant $(\sim 25 \%)$ because steric hindrance at position $\mathrm{B}$ induced by the $\mathrm{C}-\mathrm{C}-\mathrm{sp}^{2}$ benzylimidazole moiety is smaller than the one caused by a C-sp ${ }^{3}$ methyl substituent.

In conclusion, the present work adds to the growing evidence that the coordination environment at non-heme sites opens reactivity scenarios unattainable by hemes. Here we have shown that systematic tuning of the steric properties of the two sites in the cis- $\mathrm{Fe}(\mathrm{O})(\mathrm{X})$ unit translates into systematic differences in relative reactivity of the two iron-oxo tautomers. We postulate that analogous steric conditions may influence the relative reactivities of putative tautomers in non-heme iron oxygenases.

This work has been supported by the European Union (the Erasmus Mundus program), the International Research Training Group Metal Sites in Biomolecules: Structures, Regulation and Mechanisms (www.biometals.eu), and COST Action CM1003. M.C. acknowledges ERC-29910, MINECO of Spain for CTQ201237420-C02-01/BQU and CSD2010-00065, catalan DIUE (2009SGR637) and an ICREA academia award. J.Ll. thanks MICINN for a RyC contract. We thank Prof. Albert A. Shteinman for fruitful discussions and Dr Santanu Mandal for ${ }^{13} \mathrm{C}-\mathrm{NMR}$ measurements.

\section{Notes and references}

$\ddagger$ Analogous product yields and $\mathrm{A} / \mathrm{K}$ selectivity values were obtained when $\mathrm{H}_{2} \mathrm{O}$ (1000 equiv.) was not specifically added.

1 (a) T. Newhouse and P. S. Baran, Angew. Chem., Int. Ed., 2011, 50, 3362-3374; (b) L. McMurray, F. O'Hara and M. J. Gaunt, Chem. Soc. Rev., 2011, 40, 1885-1898; (c) M. Bordeaux, A. Galarneau and J. Drone, Angew. Chem., Int. Ed., 2012, 51, 10712-10723.

2 (a) C. E. Tinberg and S. J. Lippard, Acc. Chem. Res., 2011, 44, 280-288; (b) M. Costas, M. P. Mehn, M. P. Jensen and L. Que Jr., Chem. Rev., 2004, 104, 939-986; (c) M. M. Abu-Omar, A. Loaiza and N. Hontzeas, Chem. Rev., 2005, 105, 2227-2252; (d) E. G. Kovaleva and J. D. Lipscomb, Nat. Chem. Biol., 2008, 4, 186-193.

3 (a) J. T. Groves, Cytochrome P-450. Structure, Mechanism, and Biochemistry, ed. P. R. Ortiz de Montellano, Plenum Press, New York, 2005, pp. 1-43; (b) P. R. Ortiz de Montellano, Chem. Rev., 2010, 110, 932-948.

4 (a) D. T. Gibson and R. E. Parales, Curr. Opin. Biotechnol., 2000, 11, 236-243; (b) A. Karlsson, J. V. Parales, R. E. Parales, D. T. Gibson, H. Eklund and S. Ramaswamy, Science, 2003, 299, 1039-1042.

5 (a) J. T. Groves, G. A. McClusky, R. E. White and M. J. Coon, Biochem. Biophys. Res. Commun., 1978, 81, 154-160; (b) S. Chakrabarty, R. N. Austin, D. Deng, J. T. Groves and J. D. Lipscomb, J. Am. Chem. Soc., 2007, 129, 3514-3515.

6 D. P. Galonić, E. W. Barr, C. T. Walsh, J. M. Bollinger and C. Krebs, Nat. Chem. Biol., 2007, 3, 113-116.

7 (a) L. Que and W. B. Tolman, Nature, 2008, 455, 333-340; (b) M. C. White, Science, 2012, 335, 807-809; (c) E. B. Bauer, Curr. Org. Chem., 2008, 12, 1341-1369.

8 (a) K. Chen and L. Que Jr., J. Am. Chem. Soc., 2001, 123, 6327-6337; (b) J. Yoon, S. A. Wilson, Y. K. Jang, M. S. Seo, K. Nehru, B. Hedman, K. O. Hodgson, E. Bill, E. I. Solomon and W. Nam, Angew. Chem., Int. Ed., 2009, 48, 1257-1260; (c) S. H. Lee, J. H. Han, H. Kwak, S. J. Lee, E. Y. Lee, H. J. Kim, J. H. Lee, C. Bae, S. N. Lee, Y. Kim and C. Kim, Chem.-Eur. J., 2007, 13, 9393-9398; (d) I. Prat, A. Company, V. Postils, X. Ribas, L. Que, J. M. Luis and M. Costas, Chem.-Eur. J., 2013, 19, 6724-6738; (e) Y. Hitomi, K. Arakawa, T. Funabiki and M. Kodera, Angew. Chem., Int. Ed., 2012, 51, 3448-3452.

9 DFT calculations indicate that the isomeric peroxide $\mathbf{P}_{\mathbf{A}}$ is not implicated in chemistry. See ref. $8 d$.

10 (a) D. Quinonero, K. Morokuma, D. G. Musaev, R. Mas-Balleste and L. Que Jr., J. Am. Chem. Soc., 2005, 127, 6548-6549; (b) A. Bassan, M. R. A. Blomberg, P. E. M. Siegbahn and L. Que Jr., J. Am. Chem. Soc., 2002, 124, 11056-11063.

11 (a) I. Prat, J. S. Mathieson, M. Guell, X. Rivas, J. M. Luis, L. Cronin and M. Costas, Nat. Chem., 2011, 3, 788-793; (b) W. N. Oloo, A. J. Fielding and L. Que Jr., J. Am. Chem. Soc., 2013, 135, 6438-6441.

12 (a) D. Blakesley, S. C. Payne and K. S. Hagen, Inorg. Chem., 2000, 39, 197-198; (b) Y. Zang, J. Kim, Y. Dong, E. C. Wilkinson, E. H. Appelman and L. Que Jr., J. Am. Chem. Soc., 1997, 119, 4197-4205.

13 (a) J. England, C. R. Davies, M. Banaru, A. J. P. White and G. J. P. Britovsek, Adv. Synth. Catal., 2008, 350, 883-897; (b) G. J. P. Britovsek, J. England and A. J. P. White, Inorg. Chem., 2005, 44, 8125-8134; (c) P. Comba, M. Maurer and P. Vadivelu, Inorg. Chem., 2009, 48, 10389-10396; (d) Y. Mekmouche, S. Ménage, C. Toia-Duboc, M. Fontecave, J.-B. Galey, C. Lebrun and J. Pecaut, Angew. Chem., Int. Ed., 2001, 40, 949-952; (e) Y. He, J. D. Gorden and C. R. Goldsmith, Inorg. Chem., 2011, 50, 12651-12660. 